\title{
Ubiquitous Quantum Dot-sensitized Nanoporous Film for Hydrogen Production under Visible-light Irradiation
}

\author{
Masahiro Miyauchi $^{\text {a, b, *, Yuhiro Shiga }}{ }^{\text {a }}$, Nagarajan Srinivasan ${ }^{\text {a }}$, Daiki Atarashi ${ }^{\text {a }}$, Etsuo Sakai ${ }^{\text {a }}$ \\ ${ }^{a}$ Department of Metallurgy and Ceramic Science, Graduate School of Science and Engineering, \\ Tokyo Institute of Technology, 2-12-1 Ookayama, Meguro-ku, Tokyo 152-8552, Japan \\ b JST, PRESTO, 4-1-8 Honcho, Kawaguchi, Saitama 332-0012, Japan \\ * Corresponding author. Fax: +81 357342527 , \\ E-mail address: mmiyauchi@ ceram.titech.ac.jp (M. Miyauchi)
}




\begin{abstract}
To develop the efficient photocatalytic hydrogen production device, tin monosulfide (SnS) quantum dots (QDs) were deposited onto a nanoporous $\mathrm{TiO}_{2}$ electrode by the successive ionic layer adsorption and reaction (SILAR) method. When Pt nanoparticles as cocatalysts were modified at the interface between the electroconductive glass substrate and nanoporous $\mathrm{SnS}$ QDs/TiO 2 layer, hydrogen molecules were produced under visible-light irradiation without applying a bias potential. In addition, the size and color of SnS QDs could be tailored using SILAR method, and the optimal structure of the SnS QDs was determined for efficient photocurrent generation and hydrogen production. The photocatalysis device developed in the present study was constructed as a simple single plate consisting of non-toxic elements.
\end{abstract}

Key words:

chalcogenides; nanostructures; semiconductors; nanoporous materials 


\section{Introduction}

Since the discovery over 40 years ago that titanium dioxide $\left(\mathrm{TiO}_{2}\right)$ electrodes are capable of water splitting under ultra-violet (UV) light irradiation, [1] numerous semiconductor compounds have been evaluated as light-harvesting materials. In particular, metal chalcogenides, such as sulfides and selenides, are attractive light-harvesting materials because of their strong visible-light absorption, which is largely within the solar spectrum. The valence bands of metal chalcogenides consist of the p-orbitals of sulfur or selenium, which are shallower than those of metal oxides. The potential of metal chalcogenides photocatalysts, including cadmium sulfide $(\mathrm{CdS})$ and cadmium selenide (CdSe), as visible-light-sensitive photocatalysts has been evaluated in numerous studies, [2-15] but these materials are unstable under light irradiation in aqueous media. Metal chalcogenides are highly susceptible to photo-corrosion when used as light absorbers for solar water splitting.[16-18]

Quantum dot (QD)-sensitized solar cells (QDSSCs) were developed in the 1990s as photoelectrodes with sunlight-harvesting capacity.[19-26] QDSSCs are typically composed of nanometer-sized CdS and/or CdSe QDs that are deposited on nanoporous $\mathrm{TiO}_{2}$ electrodes. Similar to dye-sensitized solar cells, the electrolyte solution of QDSSCs is filled in the gap between the photoanode and counter electrode; however, polysulfide ions and sulfur molecules are utilized as redox couples in QDSSCs to avoid the photo-corrosion of QDs by oxidation reaction. QDs have many attractive characteristics for use as photo-catalysts such as multi-exciton generation, tunable 
color through the quantum size effect, and ballistic mobility of the charge carrier. The solar-cell efficiencies of QDSSCs have recently exceeded 7\%,[24, 25], and we previously found that the ratio of incident photons to current efficiencies (IPCE) of QDSSCs exceeds 80\% under short circuit conditions without application of a bias potential.[27-29]

The high IPCE values of QDSSCs under short circuit conditions suggest these materials are suitable for the construction of thin film device without bias potential. However, in order to drive the chemical reactions necessary for hydrogen evolution, the surface of QDs must be modified with an effective cocatalyst. In the present paper, we focused on constructing a $\mathrm{QD} / \mathrm{TiO}_{2}$ thin film for photocatalytic hydrogen evolution, as illustrated in Figure 1. Different from QDSSCs, platinum (Pt) nanoparticles were deposited between a fluorine-doped tin oxide (FTO)-coated transparent electroconductive glass substrate and nanoporous $\mathrm{QDs} / \mathrm{TiO}_{2}$ layer to promote hydrogen evolution. Furthermore, we consider additional important requirement on the chemical composition of the QDs for the development of unique photocatalytic device. To date, efficient photovoltaic properties have mainly been reported for QDs composed of toxic and/or rare elements, such as CdS, CdSe, $\mathrm{CeTe}, \mathrm{PbS}$, and $\mathrm{CuIn}_{\mathrm{x}} \mathrm{Ga}_{1-\mathrm{x}} \mathrm{Se}_{2}$. Recently, the concept of "ubiquitous strategy" for industrial activities have attracted considerable attention [30] Ubiquitous means existing or being everywhere especially at the same time, and can be applied to the development of photocatalysts from non-toxic and abundant resources for use in practical applications. In the present paper, we focused on tin monosulfide (SnS), which is a group IV-VI chalcogenide semiconductor, because it is composed of 
low-toxicity and inexpensive elements, and has a narrow band gap that is active in the visible-light range.[31, 32] Solid SnS films have been fabricated by electrochemical deposition [33, 34] and solution-based coating processes, $[35,36]$ and nanoparticles of $\mathrm{SnS}$ can be synthesized using a wet chemical method. [37-45] We previously reported the tailored synthesis of SnS QDs with various colors by the successive ionic layer absorption and reaction (SILAR) method and tailored the colors based on the size of the $\mathrm{SnS}$ particles. In addition to these previous studies, the photocatalytic properties, such as dye degradation reactions have been reported, [45-48] but the targeted construction of visible-light sensitive photocatalysts for energy production reactions with positive Gibbs free energy, such as those required for hydrogen production, remains challenging. [49]

Herein, we describe the fabrication of thin film based photocatalytic devices comprised of semiconductor electrodes modified with SnS QDs for efficient hydrogen production. We investigated the hydrogen production properties of these materials in the presence of polysulfide as a sacrificial agent and without the application of a bias potential.

\section{Experimental methods}

\section{1. Fabrication of $\mathrm{Pt} / \mathrm{SnS} \mathrm{QDs} / \mathrm{TiO}_{2}$ electrodes}

Platinum (Pt) nanoparticles were deposited onto a fluorine doped tin oxide (FTO-coated transparent electroconductive glass substrate by DC magnetron sputtering (MSP-30T; Shinku Device Ltd.). Prior to Pt deposition, the surfaces of the FTO substrates were ultrasonically 
degreased in ethanol for $30 \mathrm{~min}$. The thickness of the Pt layer was $25 \mathrm{~nm}$, as estimated by the sputtering time and deposition rate of the apparatus.

A dense $\mathrm{TiO}_{2}$ passivation layer was coated over the Pt layer by spin coating with a metal alkoxide solution, which was composed of $1.5 \mathrm{~mL}$ titanium tetra-isopropoxide, $30 \mathrm{~mL}$ ethanol, 0.3 mL polyethylene glycol dimethylether, and $0.1 \mathrm{~mL}$ of a $1 \mathrm{M} \mathrm{HNO}_{3}$ aqueous solution. After the spin coating of the alkoxide solution, the substrates were dried at $80{ }^{\circ} \mathrm{C}$ for $20 \mathrm{~min}$. The thickness of the $\mathrm{TiO}_{2}$ passivation layer was determined to be $50 \mathrm{~nm}$. Nanoporous $\mathrm{TiO}_{2}$ electrodes of $7 \mu \mathrm{m}$ thickness were prepared by screen-printing a paste of commercial $\mathrm{TiO}_{2}$ powder (P-25, Degussa) onto the passivation layer. These electrodes were annealed at $400^{\circ} \mathrm{C}$ for $1 \mathrm{~h}$. For electrochemical analysis in the conventional sandwich cell configuration, Pt nanoparticles were not deposited onto FTO substrates, then the nanoporous $\mathrm{TiO}_{2}$ was directly coated on the FTO surface without Pt nanoparticles.

SnS QDs were deposited on nanoporous $\mathrm{TiO}_{2}$ electrodes by the SILAR method. Solutions containing $\mathrm{Sn}^{2+}$ (solution A) or $\mathrm{S}^{2-}$ (solution B) were prepared for SILAR deposition. In solution A, $1.2 \mathrm{mmol} \mathrm{Sr}^{2+}$ ions were dissolved in a mixture of ethylene glycol $(10 \mathrm{~mL})$ and 2, 2, 2-nitrilotriethanol (2 mL). In solution $\mathrm{B}, 1 \mathrm{mmol} \mathrm{Na}_{2} \mathrm{~S}$ was dissolved in $10 \mathrm{~mL}$ water. Nanoporous $\mathrm{TiO}_{2}$ electrodes were initially dipped into solution A for 1 min at $60{ }^{\circ} \mathrm{C}$, and the electrodes were then washed in the ethylene glycol/2, 2, 2-nitrilotriethanol $(10 \mathrm{~mL} / 2 \mathrm{~mL})$ solution. The washed electrodes were then dipped into solution B for $30 \mathrm{sec}$ at $60^{\circ} \mathrm{C}$, and washed with water. The dipping 
cycles in solutions A and B were repeated several times, and the electrodes were finally washed with ethanol and dried at $80{ }^{\circ} \mathrm{C}$ in air for $10 \mathrm{~min}$. The fabricated $\mathrm{SnS}$-modified nanoporous $\mathrm{TiO}_{2}$ electrode, which contained a layer of $\mathrm{Pt}$ nanoparticles, was denoted as the $\mathrm{Pt} / \mathrm{SnS} \mathrm{QDs} / \mathrm{TiO}_{2}$ electrode. For comparison, we also prepared a pure $\mathrm{TiO}_{2}$ electrode and an $\mathrm{SnS} / \mathrm{TiO}_{2}$ electrode without the Pt layer. In addition, a powder form of $\mathrm{SnS}$ was prepared using the same solutions with the SILAR method for XRD analysis, as the amount and crystallite size of $\mathrm{SnS}$ on nanoporous $\mathrm{TiO}_{2}$ were too small to determine the crystal phase of $\mathrm{SnS}$.

\section{2. Characterization}

An X-ray diffractometer (Rigaku, Smartlab) was used to investigate the crystal phase of the prepared SnS powders. Surface and cross-sectional images of thin-film electrodes were observed using a Hitachi S-4700 field emission electron-scanning microscope (FE-SEM). The morphology of the $\mathrm{SnS}$ QD- modified $\mathrm{TiO}_{2}$ particles was observed using a transmission electron microscope (JEOL, JEM-2010F) equipped with an energy dispersive X-ray spectroscope (EDX). For the TEM analysis, $\mathrm{SnS} \mathrm{QDs} / \mathrm{TiO}_{2}$ layers were removed from the electrode by physical abrasion and were set on a copper grid. The absorption spectra of electrodes were recorded on a JASCO V-660 UV-Vis spectrometer in diffuse-reflection mode.

\section{3. Photoelectrochemical and photocatalytic properties}

The SnS QDs/ $/ \mathrm{TiO}_{2}$ anodes without Pt nanoparticles were sealed in a sandwich cell with a 30- $\mu \mathrm{m}$ spacer and equipped with a Pt counter electrode. The $\mathrm{SnS}$ QDs/ $\mathrm{TiO}_{2}$ anode area was $0.25 \mathrm{~cm}^{2}$. A 0.1 
$\mathrm{M}$ aqueous solution containing $0.24 \mathrm{M} \mathrm{Na} 2 \mathrm{~S}$ and $0.34 \mathrm{M} \mathrm{Na}_{2} \mathrm{SO}_{3}$ as redox couples was prepared using $\mathrm{Na}_{2} \mathrm{~S} \cdot 9 \mathrm{H}_{2} \mathrm{O}$ (Kanto Chemical Co.) and $\mathrm{SnBr}_{2}$ (Sigma-Aldrich) and used as the electrolyte in the sandwich cell. The photocurrent response was measured by a potentiostat (HSV-110; Hokuto Denko Co.) using an AM 1.5 G solar simulator (PEC-L11; Peccell Co.) equipped with a $300 \mathrm{~W}$ Xe lamp and AM 1.5 filter as the light source with an UV-cutoff filter below $430 \mathrm{~nm}$ (Y-43; Asahi Techno Glass). Visible light was irradiated from the backside of the $\mathrm{SnS}$ QDs/ $/ \mathrm{TiO}_{2}$ anode.

Measurement of photocatalytic $\mathrm{H}_{2}$ evolution was performed in a closed glass cell connected to a gas-circulating system. A Pt/SnS/TiO 2 electrode with an area of $4 \mathrm{~cm}^{2}$ was placed in an aqueous electrolyte solution containing $0.24 \mathrm{M} \mathrm{Na} 2 \mathrm{~S}$ and $0.34 \mathrm{M} \mathrm{Na}_{2} \mathrm{SO}_{3}$ as the sacrificial agent. The electrolyte solution and headspace of the cell were purged with argon gas, and the cell was then illuminated with a $150 \mathrm{~W}$ Xe lamp with an UV cutoff filter below $430 \mathrm{~nm}$. The evolved $\mathrm{H}_{2}$ gas was detected by on-line gas chromatography (TCD, $0.5 \mathrm{~nm}$ molecular sieves; Shimadzu Co.) with Ar as the carrier gas.

\section{Results and discussion}

Figure 2 shows the XRD pattern for free SnS QD powder synthesized by the same starting solution of the SILAR method. All diffraction peaks were assigned to herzenbergite-type $\mathrm{SnS}$ (ICSD No. 01-071-3679). We also investigated the XRD pattern of bare nanoporous $\mathrm{TiO}_{2}$ substrate and found the crystal phase exhibited a similar mixture of anatase and rutile crystal phases to that 
reported previously.[50]

Figure 3 (a) shows a cross-sectional SEM image of the $\mathrm{Pt} / \mathrm{SnS} \mathrm{QDs}_{\mathrm{TiO}} \mathrm{T}_{2}$ electrode. The nanoporous $\mathrm{SnS}$ QDs/ $/ \mathrm{TiO}_{2}$ had a thickness of $7 \mu \mathrm{m}$. The expanded cross-sectional view of the electrode showed that the Pt nanoparticle and dense passivation $\mathrm{TiO}_{2}$ layers were uniformly coated on the FTO substrate and had thicknesses of 25 and $50 \mathrm{~nm}$, respectively (Figure 3 (b)). Surface SEM images of the $\mathrm{SnS}$-modified nanoporous $\mathrm{TiO}_{2}$ electrode and bare $\mathrm{TiO}_{2}$ electrode are shown in Figure 3 (c, d) and (e, f), respectively. After the deposition of $\mathrm{SnS}$ by the SILAR method, the $\mathrm{TiO}_{2}$ surface became rough, indicating that small $\mathrm{SnS}$ QDs were present on the surface of the $\mathrm{TiO}_{2}$ particles.

The SnS-modified $\mathrm{TiO}_{2}$ particles were further characterized by TEM analysis (Figure 4). The $\mathrm{TiO}_{2}$ particles were approximately $50 \mathrm{~nm}$ and were decorated with small particles. We observed several SnS QDs in our supporting information (Figure S1), and their diameter was less than $10 \mathrm{~nm}$. Figure 4(b) shows EDX point analysis of points (i) and (ii) in the Figure 4(a) with an electron beam size of $10 \mathrm{~nm}$. EDX signals for tin (Sn) and sulfur (S) were observed at point (ii), but these signals were not detected at point (i), indicating that the $<10 \mathrm{~nm}$ particles on the surface of the $\mathrm{TiO}_{2}$ particles were composed of SnS.

Figure 5 (a) shows the optical absorption spectra for electrodes constructed using different numbers of SILAR cycles. With increasing number of SILAR cycles, the absorption of the SnS QDs shifted towards longer wavelengths, a phenomenon that can be attributed to the quantum 
confinement effect. Figure 5 (b) shows the relationship between the optical band-gap of SnS QDs, which was determined by the square of absorption coefficient, as described in detail in the Supporting Information (Figure S2), and number of SILAR cycles. From this analysis, it is clear that the band gap of SnS QDs is dependent on the number of SILAR cycles. The reported band gap of bulk $\mathrm{SnS}$ is 1.0- $1.2 \mathrm{eV}$.[41] Images of pure $\mathrm{TiO}_{2}$ and $\mathrm{SnS}$ QDs/ $\mathrm{TiO}_{2}$ electrodes constructed using 10 SILAR cycles are shown in our Supporting Information (Figure S3). After SILAR treatment, the $\mathrm{TiO}_{2}$ electrode turned brown in color. Notably, the color change was obvious even from the reverse side of the FTO glass, indicating that the $\mathrm{SnS}$ QDs had diffused into the nanoporous $\mathrm{TiO}_{2}$ electrode and were deposited near the interface of the compact $\mathrm{TiO}_{2}$ layer.

We next investigated the photocurrent generated by the $\mathrm{SnS}$ QDs/ $/ \mathrm{TiO}_{2}$ electrode in the sandwich cell configuration. Short circuit photocurrent was measured under a solar simulator equipped with an AM 1.5 G filter and UV cutoff filter. Figure 6 (a) shows the photocurrent generated under the chopping visible-light irradiation by the bare $\mathrm{TiO}_{2}$ and $\mathrm{SnS}$ QDs/ $\mathrm{TiO}_{2}$ electrodes prepared using 10 SILAR cycles. Only a small photocurrent was detected for the bare $\mathrm{TiO}_{2}$ electrode, as the optical filter could not completely cutoff UV light within the solar simulator, which caused band-gap excitation of $\mathrm{TiO}_{2}$ itself. In contrast, a much higher photocurrent was generated by the $\mathrm{SnS}$ QDs/ $/ \mathrm{TiO}_{2}$ electrode, owing to direct photo-excitation of the SnS QDs. The photocurrent of the SnS QDs/ $/ \mathrm{TiO}_{2}$ electrode gradually decreased under the visible-light irradiation due to photo-degradation of the SnS QDs, which is generally seen in other metal chalcogenides QDs like CdS and CdSe 
[16-18]. We compared the photocurrent densities of $\mathrm{SnS}$ QDs/ $\mathrm{TiO}_{2}$ electrodes prepared with different numbers of SILAR cycles using the second visible-light irradiation interval (Figure 6 (b)). Based on a comparison of the maximum photocurrent density, approximately 10 SILAR cycles was found to yield efficient photocurrent generation by the $\mathrm{SnS}$ QDs/ $/ \mathrm{TiO}_{2}$ electrode. With fewer SILAR cycles, the number of electron-hole pairs is reduced due to the limited optical absorption. On the other hand, as the number of SILAR cycles increases, the $\mathrm{TiO}_{2}$ electrode surface becomes overloaded with SnS QDs, which limits hole transfer from SnS QDs and the diffusion of electrolyte agents to the SnS QDs. In addition to the limited carrier and electrolyte diffusion, band-gap narrowing would also decrease the oxidation and/or reduction potential of SnS QDs semiconductors.

Finally, the rate of hydrogen generation under visible-light irradiation was determined for the $\mathrm{Pt} / \mathrm{TiO}_{2}, \mathrm{SnS} \mathrm{QDs} / \mathrm{TiO}_{2}$, and Pt/SnS QDs/TiO 2 electrodes (Figure 7). The number of SILAR cycles for this experiment was fixed at 10, which was determined to be yield optimal photocurrent density. The $\mathrm{Pt} / \mathrm{TiO}_{2}$ electrode did not exhibit hydrogen generation, as it did not absorb visible light. Hydrogen generation from the $\mathrm{SnS}$ QDs/ $\mathrm{TiO}_{2}$ electrode was also very limited, because the electrons injected from $\mathrm{SnS}$ QDs into $\mathrm{TiO}_{2}$ could not efficiently produce hydrogen. As the hydrogen evolution reaction involves a two-electron reduction process, cocatalyst promoters, such as $\mathrm{Pt}$ nanoparticles, are typically required to generate hydrogen. In contrast, the $\mathrm{Pt} / \mathrm{SnS} \mathrm{QDs} / \mathrm{TiO}_{2}$ electrode exhibited efficient hydrogen production, even under non-biased conditions. 
In the present study, we successfully constructed a photo-electrode with a nanoporous film structure using abundant elements and non-toxic QDs and demonstrated that the electrode evolves hydrogen under visible-light irradiation without the application of a bias potential. However, the photocatalytic properties of the $\mathrm{Pt} / \mathrm{SnS} \mathrm{QDs} / \mathrm{TiO}_{2}$ electrode gradually decreased with long-term light irradiation due to photo-corrosion of the materials, which is a disadvantageous characteristic of metal chalcogenides. However, the present results suggest that these materials may be suitable for practical photocatalytic applications if the stability of $\mathrm{SnS}$ QDs can be improved through passivation or other modification procedures.

\section{Conclusion}

The SnS QD-modified $\mathrm{TiO}_{2}$ electrode prepared with $\mathrm{Pt}$ nanoparticles exhibited hydrogen evolution under visible-light irradiation without the application of a bias potential. The size and color of the SnS QDs could be tailored using SILAR method, and the optimum structure of SnS QDs was explored for efficient photocurrent generation and hydrogen production. As the constructed thin film device consists of non-toxic and inexpensive elements, it has advantageous properties compared to previously reported QD-sensitized electrodes.

\section{Acknowledgement}

We thank Mr. A. Genseki and Mr. J. Koki at the Center for Advanced Materials Analysis of the 
Tokyo Institute of Technology for performing TEM and SEM observations. We also acknowledge

Mr. Greg Newton for the critical reading of the manuscript. This research was supported by JST,

\section{PRESTO.}

\section{References}

[1] A. Fujishima, K. Honda, Nature, 238 (1972) 37-38.

[2] H. Gerischer, Journal of Electroanalytical Chemistry and Interfacial Electrochemistry, 58 (1975) 263-274.

[3] H. Tributsch, Journal of The Electrochemical Society, 125 (1978) 1086-1093.

[4] M. Graetzel, Accounts of chemical research, 14 (1981) 376-384.

[5] L.F. Schneemeyer, B. Miller, Journal of The Electrochemical Society, 129 (1982) 1977-1981.

[6] M. Matsumura, Y. Saho, H. Tsubomura, The Journal of Physical Chemistry, 87 (1983) 3807-3808.

[7] D.E. Aspnes, A. Heller, The Journal of Physical Chemistry, 87 (1983) 4919-4929.

[8] A.W.H. Mau, C.B. Huang, N. Kakuta, A.J. Bard, A. Campion, M.A. Fox, J.M. White, S.E. Webber, Journal of the American Chemical Society, 106 (1984) 6537-6542.

[9] S. Kohtani, A. Kudo, T. Sakata, Chemical Physics Letters, 206 (1993) 166-170.

[10] I. Tsuji, H. Kato, A. Kudo, Angew. Chem. Int. Ed. 117 (2005) 3631-3634.

[11] Y. Tak, S.J. Hong, J.S. Lee, K. Yong, J. Mater. Chem., 19 (2009) 5945-5951.

[12] J. Hensel, G. Wang, Y. Li, J.Z. Zhang, Nano Lett, 10 (2010) 478-483.

[13] W. W. Xiong, J. Miao, P. Z. Li, Y. Zhao, B. Liub, Q. Zhang, CrystEngComm, 16 (2014) 5989-5992.

[14] Y. Liu, P. D. Kanhere, C. L. Wong, Y. Tian, Y. Feng, F. Boey, T. Wu, H. Chen, T. J. White, Z. Chen, Q. Zhang, J. Solid State Chem. 183 (2010) 2644-2649.

[15] J. Gao, Q. Tay, P.-Z. Li, W.-W. Xiong, Y. Zhao, Z. Chen, Q. Zhang, Chem. Asian J, 9 (2014) 131-134.

[16] H. Yan, J. Yang, G. Ma, G. Wu, X. Zong, Z. Lei, J. Shi, C. Li, Journal of Catalysis, 266 (2009) 165-168.

[17] C.F. Chi, S.Y. Liau, Y.L. Lee, Nanotechnology, 21 (2010) 025202.

[18] Y.-L. Lee, C.-F. Chi, S.-Y. Liau, Chemistry of Materials, 22 (2010) 922-927.

[19] D. Liu, P.V. Kamat, The Journal of Physical Chemistry, 97 (1993) 10769-10773.

[20] R. Vogel, P. Hoyer, H. Weller, The Journal of Physical Chemistry, 98 (1994) 3183-3188.

[21] L. Kronik, N. Ashkenasy, M. Leibovitch, E. Fefer, Y. Shapira, S. Gorer, G. Hodes, Journal of The Electrochemical Society, 145 (1998) 1748-1755.

[22] A.J. Nozik, Physica E: Low-dimensional Systems and Nanostructures, 14 (2002) 115-120.

[23] Q. Shen, D. Arae, T. Toyoda, Journal of Photochemistry and Photobiology A: Chemistry, 164 (2004) 75-80.

[24] A.H. Ip, S.M. Thon, S. Hoogland, O. Voznyy, D. Zhitomirsky, R. Debnath, L. Levina, L.R. Rollny, G.H. Carey, A. Fischer, K.W. Kemp, I.J. Kramer, Z. Ning, A.J. Labelle, K.W. Chou, A. Amassian, E.H. Sargent, Nat Nano, 7 (2012) 577-582. 
[25] J. Jean, S. Chang, P.R. Brown, J.J. Cheng, P.H. Rekemeyer, M.G. Bawendi, S. Gradečak, V. Bulović, Advanced materials, 25 (2013) 2790-2796.

[26] M. Ye, J. Gong, Y. Lai, C. Lin, Z. Lin, J. Am. Chem. Soc., 134 (2012) 15720-15723.

[27] Z. Liu, M. Miyauchi, Y. Uemura, Y. Cui, K. Hara, Z. Zhao, K. Sunahara, A. Furube, Applied Physics Letters, 96 (2010) 233107.

[28] Z. Liu, Y. Li, Z. Zhao, Y. Cui, K. Hara, M. Miyauchi, Journal of Materials Chemistry, 20 (2010) 492-497.

[29] H. Wang, M. Miyauchi, Y. Ishikawa, A. Pyatenko, N. Koshizaki, Y. Li, L. Li, X. Li, Y. Bando, D. Golberg, Journal of the American Chemical Society, 133 (2011) 19102-19109.

[30] H. Hideo, H. Katsuro, K. Toshio, A. Toshiyuki, S. Tomofumi, Science and Technology of Advanced Materials, 12 (2011) 034303.

[31] M. Ichimura, Solar Energy Materials and Solar Cells, 93 (2009) 375-378.

[32] L. Makinistian, E.A. Albanesi, physica status solidi (b), 246 (2009) 183-191.

[33] N. Sato, M. Ichimura, E. Arai, Y. Yamazaki, Solar Energy Materials and Solar Cells, 85 (2005) 153-165.

[34] K. Mishra, K. Rajeshwar, A. Weiss, M. Murley, R.D. Engelken, M. Slayton, H.E. McCloud, Journal of The Electrochemical Society, 136 (1989) 1915-1923.

[35] N. Koteeswara Reddy, K.T. Ramakrishna Reddy, Materials Chemistry and Physics, 102 (2007) 13-18.

[36] D. Avellaneda, M.T.S. Nair, P.K. Nair, Journal of The Electrochemical Society, 155 (2008) D517-D525.

[37] Y. Xu, N. Al-Salim, C.W. Bumby, R.D. Tilley, Journal of the American Chemical Society, 131 (2009) 15990-15991.

[38] E.C. Greyson, J.E. Barton, T.W. Odom, Small, 2 (2006) 368-371.

[39] D. Koktysh, J. McBride, S. Rosenthal, Nanoscale research letters, 2 (2007) 144-148.

[40] S. Schlecht, L. Kienle, Inorganic Chemistry, 40 (2001) 5719-5721.

[41] S.G. Hickey, C. Waurisch, B. Rellinghaus, A. Eychmüller, Journal of the American Chemical Society, 130 (2008) 14978-14980.

[42] Y. Wang, H. Gong, B. Fan, G. Hu, The Journal of Physical Chemistry C, 114 (2010) 3256-3259.

[43] Y. Wang, Y.B. Reddy, H. Gong, Journal of The Electrochemical Society, 156 (2009) H157-H160.

[44] H. Tsukigase, Y. Suzuki, M.-H. Berger, T. Sagawa, S. Yoshikawa, Journal of Nanoscience and Nanotechnology, 11 (2011) 1914-1922.

[45] J. Chao, Z. Xie, X. Duan, Y. Dong, Z. Wang, J. Xu, B. Liang, B. Shan, J. Ye, D. Chen, G. Shen, CrystEngComm, 14 (2012) 3163-3168.

[46] C. Yang, W. Wang, Z. Shan, F. Huang, Journal of Solid State Chemistry, 182 (2009) 807-812.

[47] Y.C. Zhang, Z.N. Du, S.Y. Li, M. Zhang, Applied Catalysis B: Environmental, 95 (2010) 153-159.

[48] P. Tang, H. Chen, F. Cao, G. Pan, K. Wang, M. Xu, Y. Tong, Materials Letters, 65 (2011) 450-452.

[49] Y. Sun, Z. Sun, S. Gao, H. Cheng, Q. Liu, F. Lei, S. Wei, Y. Xie, Advanced Energy Materials, 4 (2014) 1300611.

[50] T. Ohno, K. Sarukawa, K. Tokieda, M. Matsumura, Journal of Catalysis, 203 (2001) 82-86. 


\section{Figure Captions}

Figure 1. Schematic illustrations of the device structure, electronic band structure, and nanostructure of the $\mathrm{Pt} / \mathrm{SnS} \mathrm{QDs} / \mathrm{TiO}_{2}$ electrode.

Figure 2. XRD pattern for SnS QD powder.

Figure 3. $\mathrm{SEM}$ images of the $\mathrm{Pt} / \mathrm{SnS} \mathrm{QDs} / \mathrm{TiO}_{2}$ electrode, showing a cross-sectional image (a) and expanded view of the interface between the film and substrate (b). Surface SEM images for the $\mathrm{Pt} / \mathrm{SnS}$ QDs $/ \mathrm{TiO}_{2}$ (c, d) and bare $\mathrm{TiO}_{2}$ electrodes (e, f). A total of 10 SILAR cycles were used for loading the SnS QDs.

Figure 4. TEM images of $\mathrm{SnS}$ QDs and $\mathrm{TiO}_{2}$ particles (a). Results of EDX point analysis (b) performed at points (i) and (ii) in (a). A total of 10 SILAR cycles were used for loading the $\mathrm{SnS}$ QDs.

Figure 5. UV-Vis reflectance spectra for the $\mathrm{SnS} \mathrm{QDs} / \mathrm{TiO}_{2}$ electrodes synthesized with various numbers of SILAR cycles (a). Relationship between the number of SILAR cycles and estimated bandgap value (b).

Figure 6. Short circuit photocurrent density under chopping visible-light irradiation for the Pt/SnS QDs/ $/ \mathrm{TiO}_{2}$ and bare $\mathrm{TiO}_{2}$ electrodes (a). A total of 10 SILAR cycles were used for preparation of the $\mathrm{Pt} / \mathrm{SnS} \mathrm{QDs} / \mathrm{TiO}_{2}$ electrode. Photocurrent density versus the number of SILAR cycles (b).

Figure 7. Hydrogen generation rate under visible-light irradiation. 
Figure 1
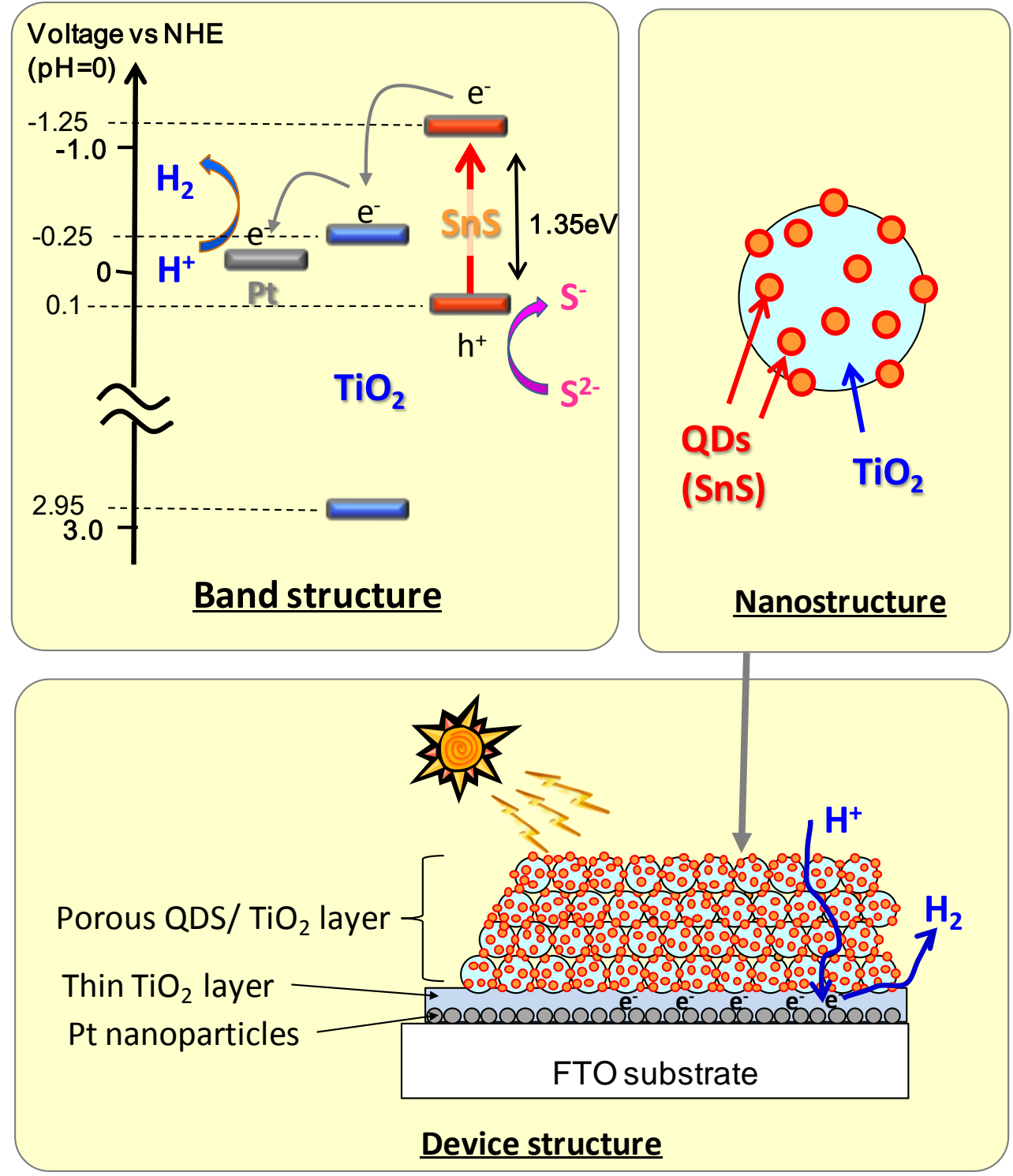
Figure 2

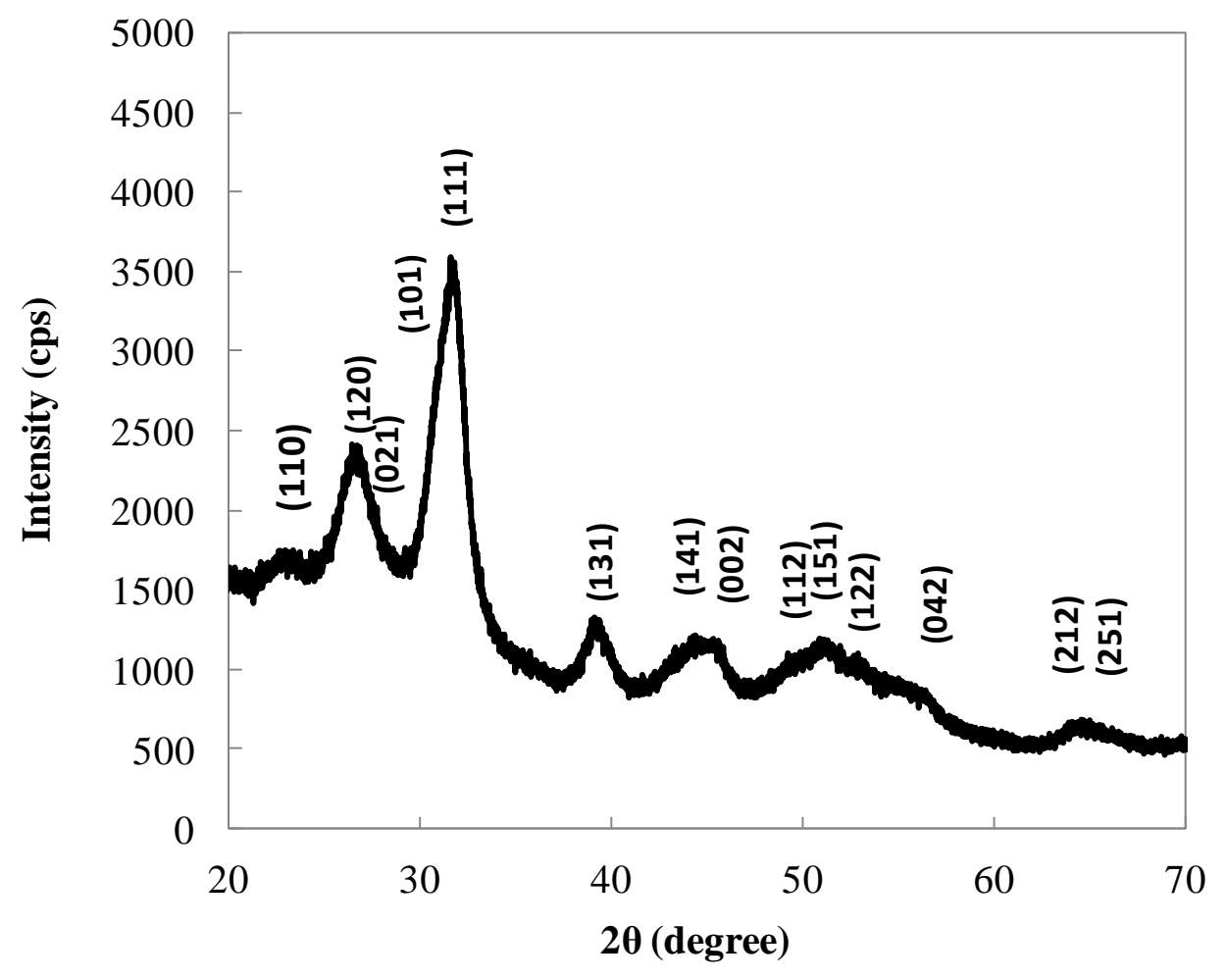


Figure 3
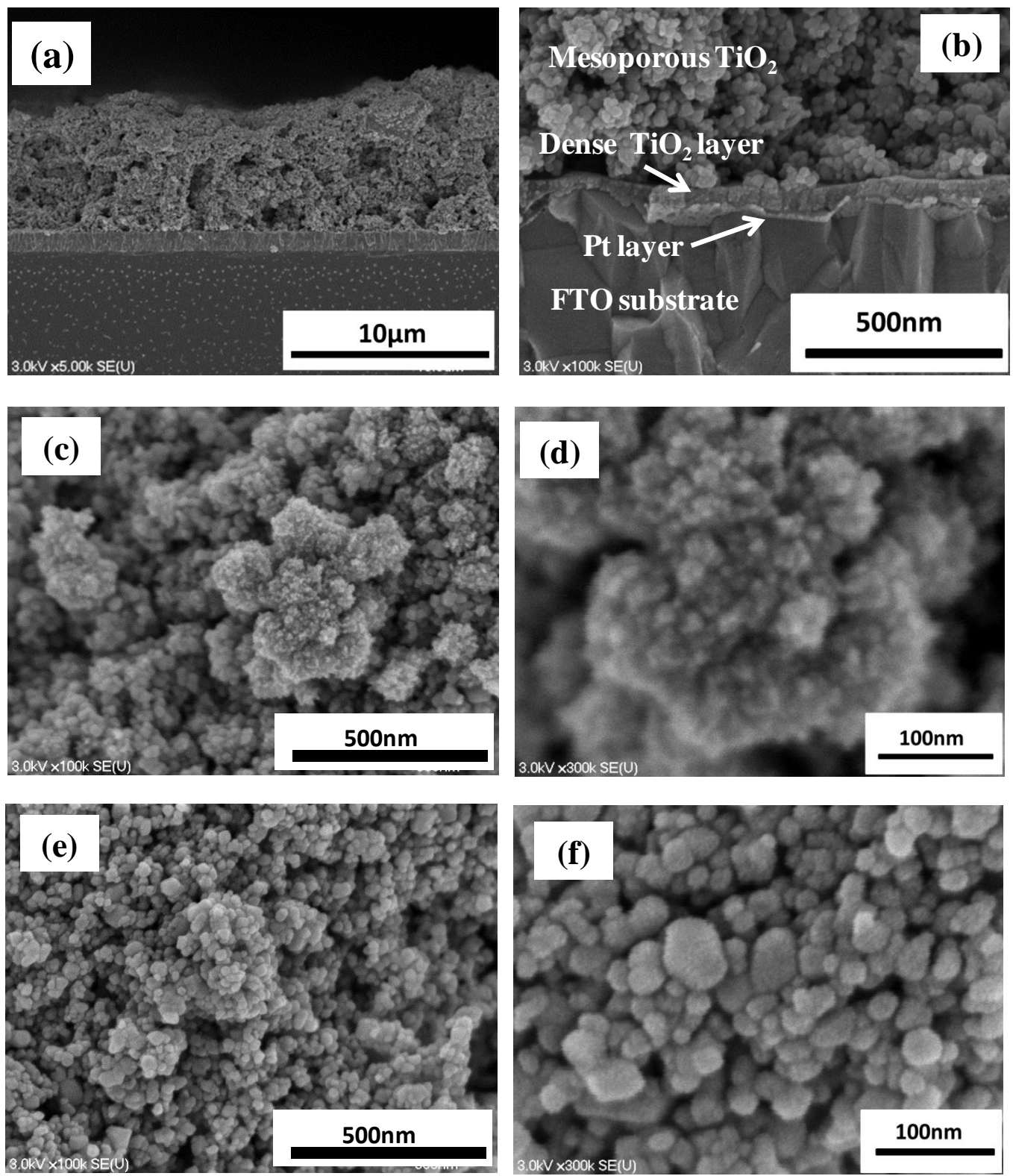
Figure 4
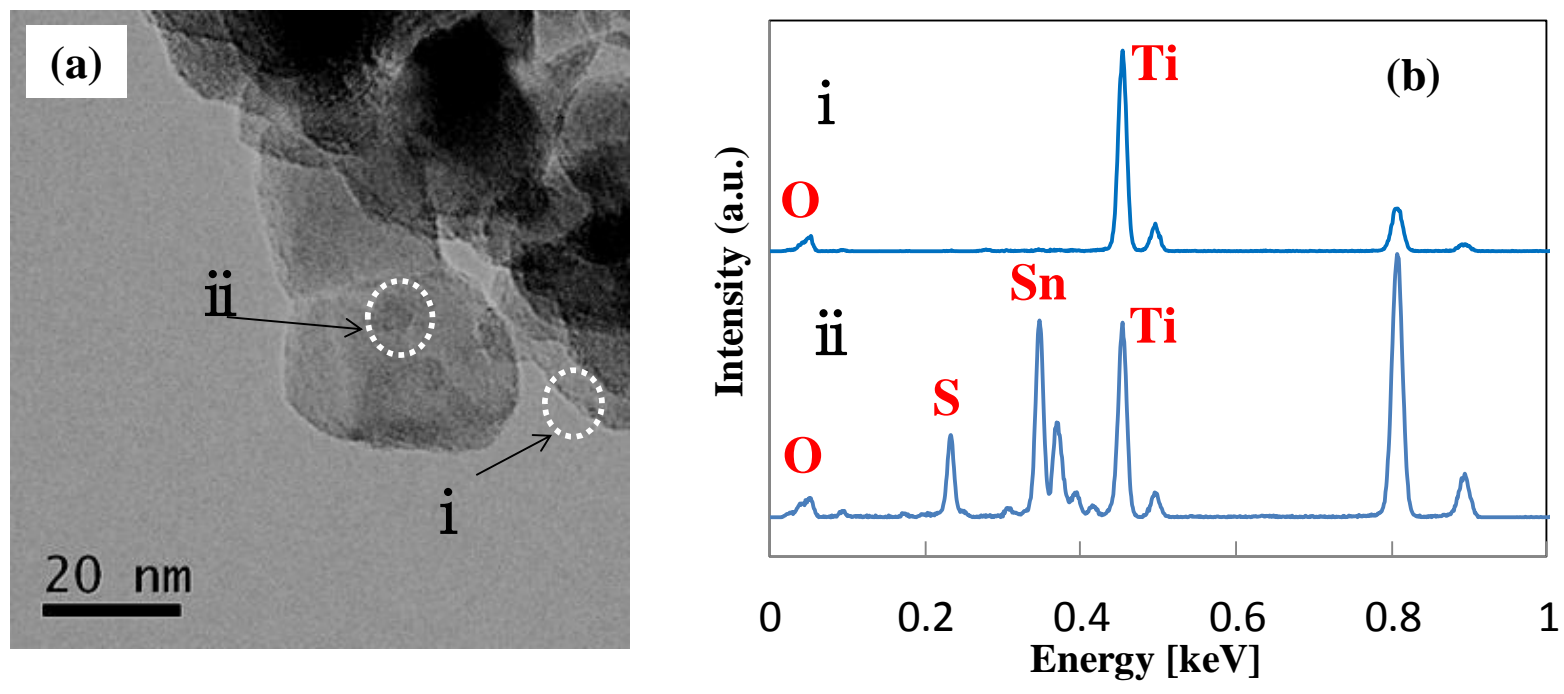
Figure 5
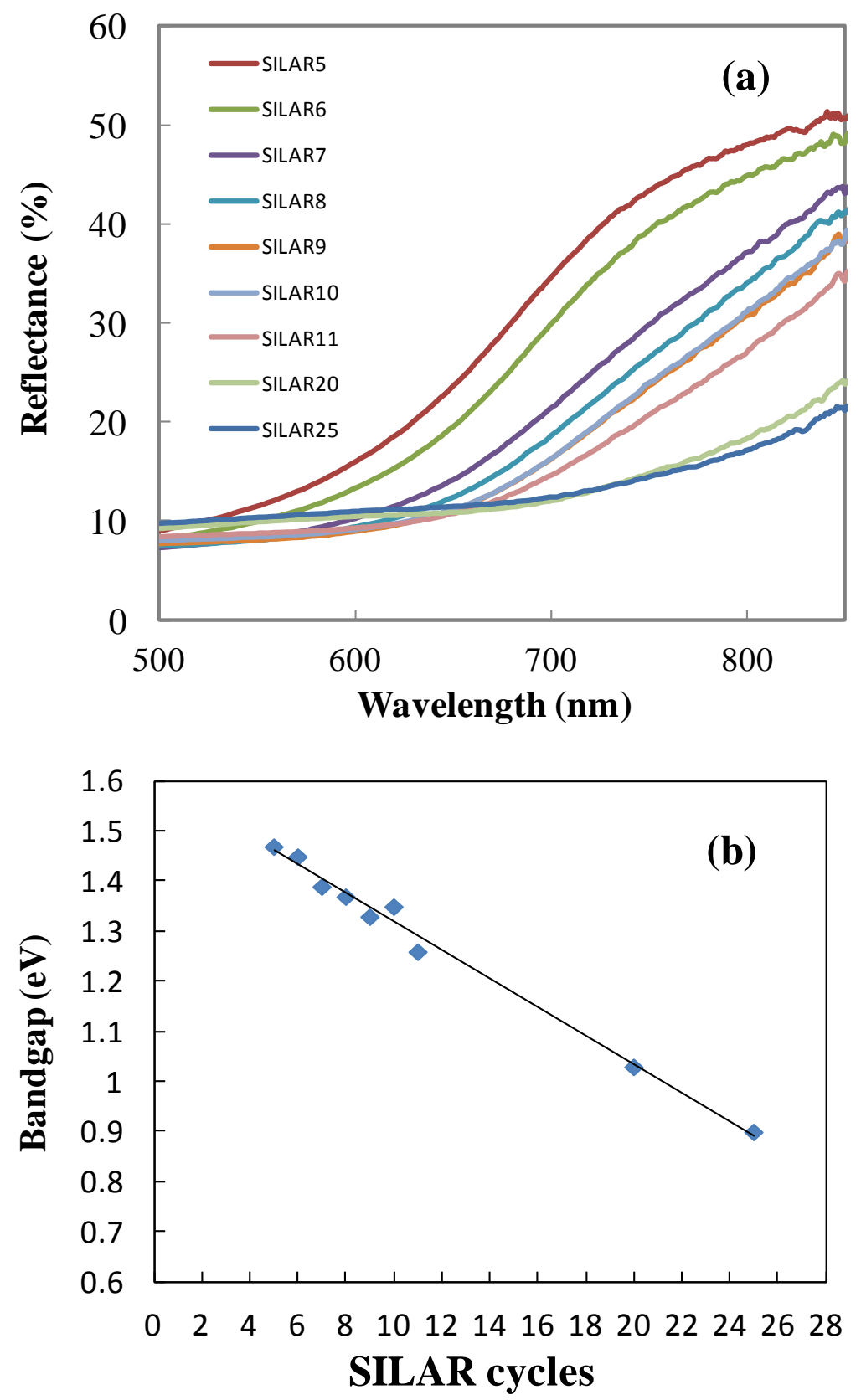
Figure 6
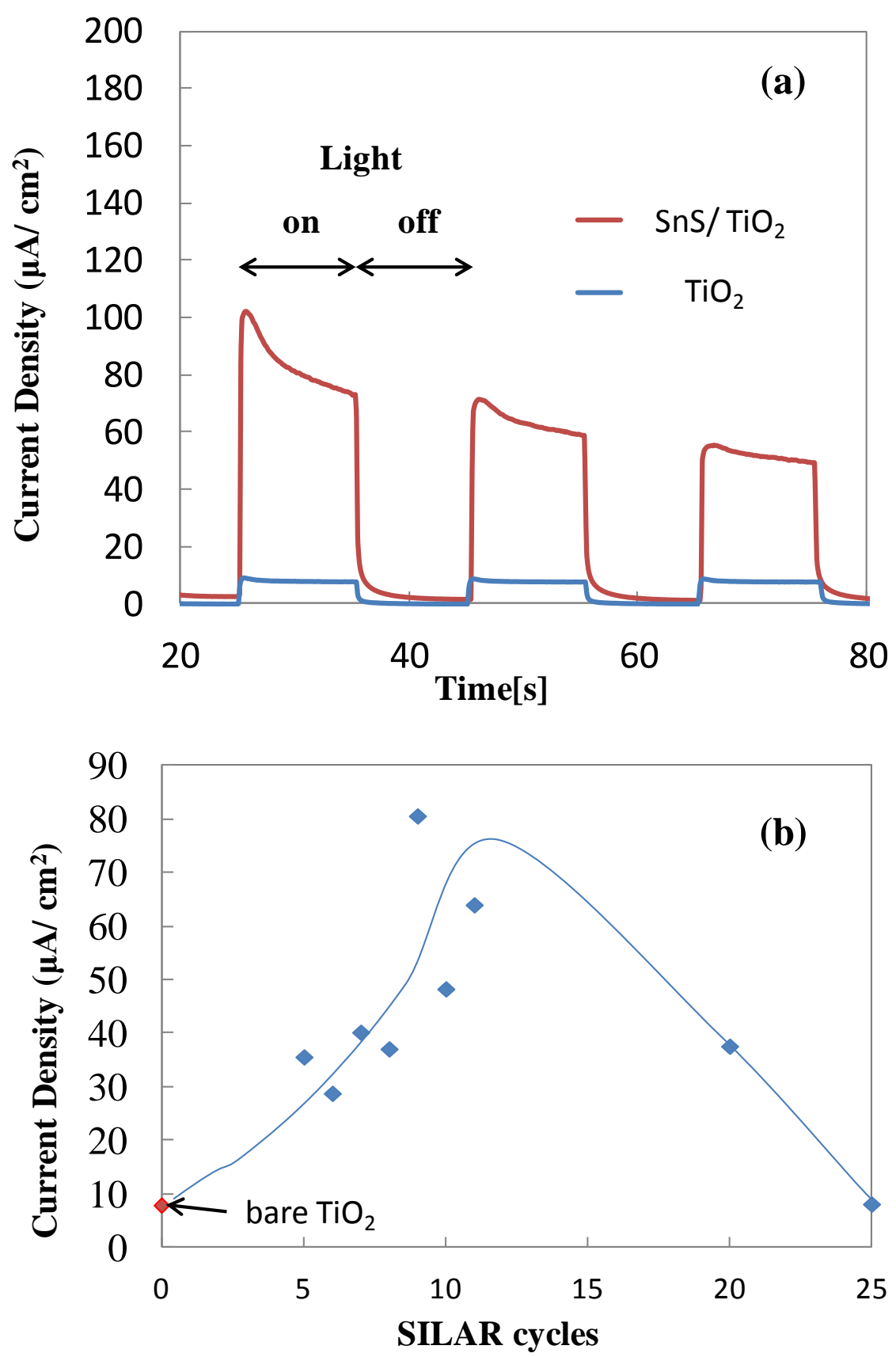
Figure 7

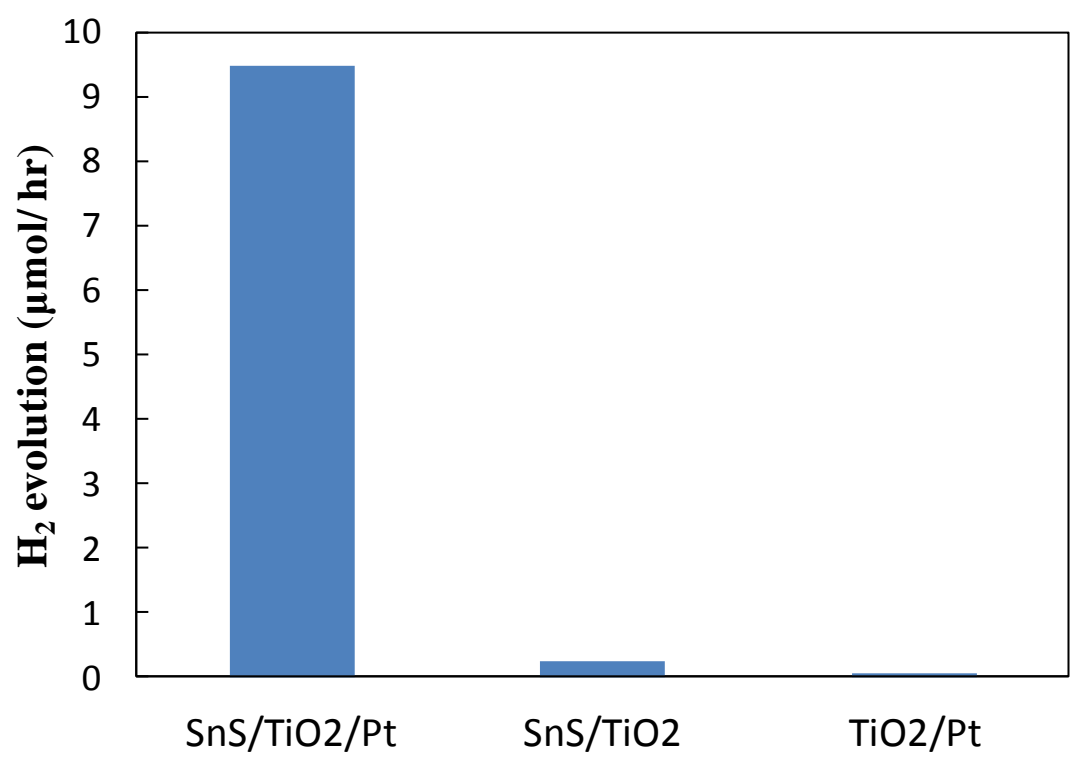




\section{Ubiquitous Quantum Dot-sensitized Nanoporous Film for Hydrogen Production under Visible-light Irradiation}

Masahiro Miyauchi *, Yuhiro Shiga, Nagarajan Srinivasan, Daiki Atarashi, Etsuo Sakai

\section{Graphical Abstract}

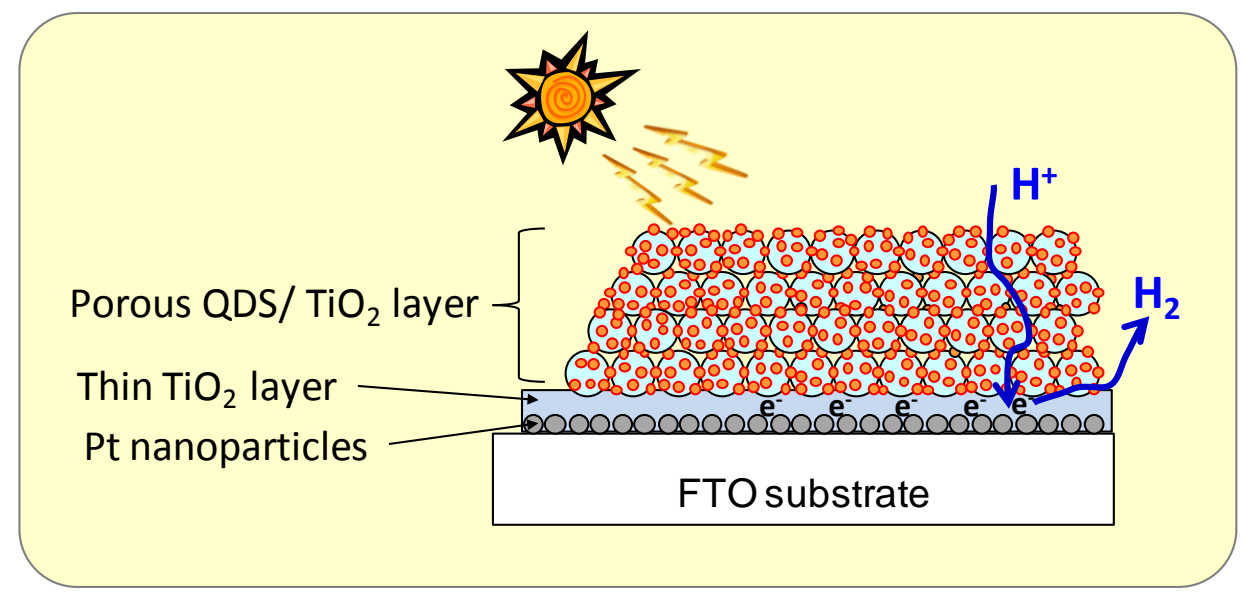

